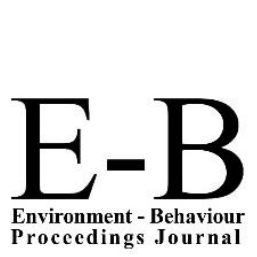

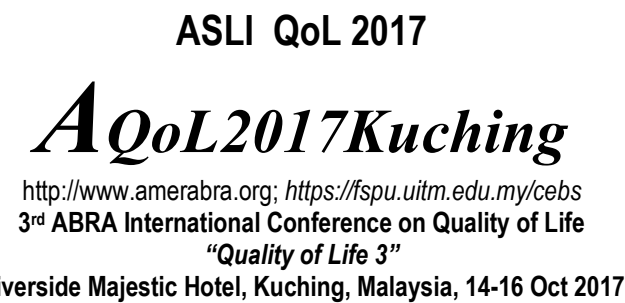

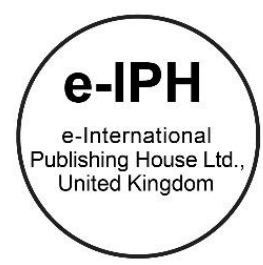

\title{
A Taste of Spatial Character: Quality outdoor space in campus landscape leisure setting
}

\author{
Norizan Mt Akhir ${ }^{*}$, Siti Rasidah Md Sakip², Mohamed Yusoff Abbas³, Noriah Othman
}

\begin{abstract}
1, 2Landscape Architecture Department, Faculty of Architecture, Planning \& Surveying, Universiti Teknologi MARA, 32610 Seri Iskandar, Perak, Malaysia ${ }^{3}$ Architecture Department, Faculty of Architecture, Planning \& Surveying, Universiti Teknologi MARA, 42300 Puncak Alam, Selangor, Malaysia ${ }^{4}$ Landscape Architecture Department, Faculty of Architecture, Planning \& Surveying, Universiti Teknologi MARA, 42300 Puncak Alam, Selangor, Malaysia
\end{abstract}

noriz102@perak.uitm.edu.my

\begin{abstract}
The landscape is important in spatial development for campus space. Fundamentally, planting composition generates a character of the outdoor space. It could offer an enormous influence on visual quality, student performance and quality of life. This paper investigated the preferences and usage of outdoor campus space provided by universities during students' leisure time. The data were collected through structured interviews at Research Universities in Malaysia. The results showed a relationship between preferences for landscape setting and utilisation index. Hence, this study suggested, the planting design is substantial to generate the space character which stimulates the use of outdoor campus space.
\end{abstract}

Keywords: Spatial character; landscape setting; outdoor campus space; quality of life

eISSN: 2398-4287@ 2017. The Authors. Published for AMER ABRA by e-International Publishing House, Ltd., UK. This is an open access article under the CC BYNCND license (http://creativecommons.org/licenses/by-nc-nd/4.0/). Peer-review under responsibility of AMER (Association of Malaysian Environment-Behaviour Researchers), ABRA (Association of Behavioural Researchers on Asians) and cE-Bs (Centre for Environment-Behaviour Studies), Faculty of Architecture, Planning \& Surveying, Universiti Teknologi MARA, Malaysia.

https://doi.org/10.21834/e-bpj.v2i6.987

\subsection{Introduction}

University is a place for critical thinking development, gushing an innovative and creative idea, and connecting the intellectual researchers and students to gain new knowledge (Stephen et. al., 2014). These activities were exposed the students to the high level of stress. Failure to control the quality of life on campus, will lead to stress and threaten their academic performance (Hamaideh, 2011). The quality of life encompasses the fulfilment of human need and satisfaction in all condition including physical, social, economy, environment and spiritual (Dasimah, 2009). On that notes, the study aims to investigate students' satisfaction through their preferences and usage of campus spaces that provided by the university. That is important to understand how students encounter, perceive and use the provided outdoor spaces and assist in future campus landscape expansion. Therefore, this study identified the favourable outdoor spaces utilised on campus and subsequently analysed the spatial characteristics of the preferred spaces.

In the context of campus space, students are the populace which needs the leisure spaces that fulfil their satisfaction for general well-being. The campus landscape leisure space defined as an outdoor area that frequently used by students for non-academic purposes such as chatting, exercising, relaxing, sightseeing and eating. The quality of landscape setting for leisure space plays a significant role in ensuring student satisfaction and motivate to utilise it again. Noriah et. al., (2015) supported that the quality of landscape leisure setting has a relationship with motivational theory. Noralizawati et. al., (2011) has explored the theory of human motivation in landscape with a natural setting. They synthesised that it is significant to measure the landscape design in the outdoor

eISSN: 2398-4287@ 2017. The Authors. Published for AMER ABRA by e-International Publishing House, Ltd., UK. This is an open access article under the CC BYNCND license (http://creativecommons.org/licenses/by-nc-nd/4.0/). Peer-review under responsibility of AMER (Association of Malaysian Environment-Behaviour Researchers), ABRA (Association of Behavioural Researchers on Asians) and cE-Bs (Centre for Environment-Behaviour Studies), Faculty of Architecture, Planning \& Surveying, Universiti Teknologi MARA, Malaysia.

https://doi.org/10.21834/e-bpj.v2i6.987 
leisure space. Besides, the successful landscape design can be determined through human's reason on something that they like and preferred to (Noralizawati et al., 2012).

\subsection{Literature Review}

\subsection{Quality of outdoor campus space}

University is a similar as one small city that accommodates the population to live in, working places, gathering with friends and others. In fact, people in a city has a park or green space to meet the need of leisure activities (i.e., recreation, exercise and sightseeing) to release stress and go to a healthy lifestyle. As well as campus, students engage with various focus activities in class which lead to attention fatigue and stress (Dongying and Sullivan, 2016). With a quality of outdoor campus space, often make the burden less. As mention by Ulrich $(1979,1981)$ initiate that students can manage stressed situations toward positive vision when they are viewing plants or another type of landscape with nature.

Research has shown that individuals that access actively to landscape with a natural setting was happier and enjoy their life (Kaplan and Kaplan, 1989). Figure 1 shows that the quality of outdoor campus is rank by the characters of the spaces. As well, the characters mostly depended on personal preferences and background.

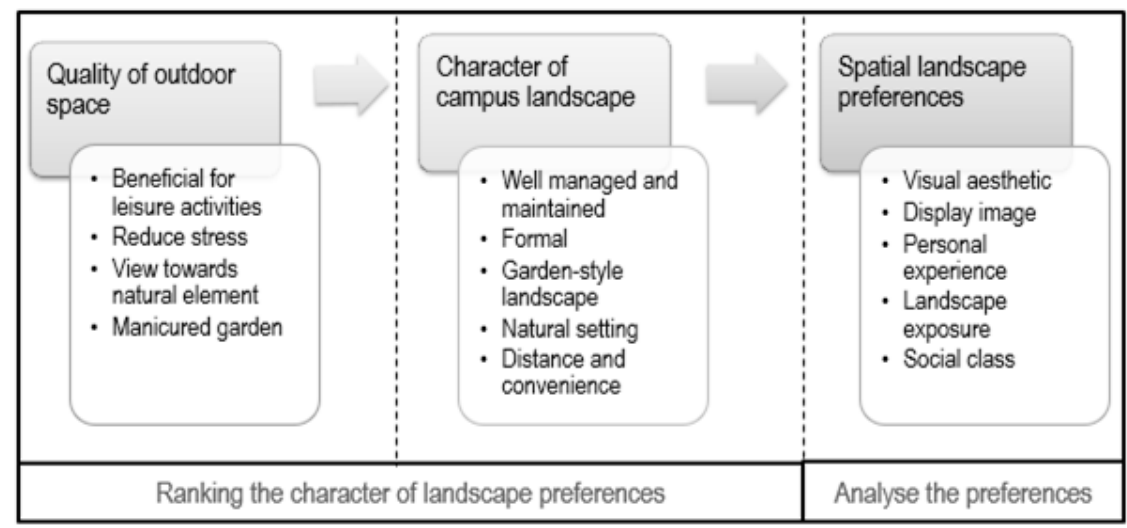

Fig. 1: Quality of outdoor spaces rank by specific characteristics

McFarland et.al., (2008) compile those previous researchers have been found more positive results on the interaction of individuals by views of vegetation, water, or nearby mountains. However, Speake et.al., (2013) argue that students are not aware of the importance of the naturalistic area. Additionally, the lack of ecological awareness is stimuli to the tendency of preferences more towards tamed and manicured landscape (Speake et.al., 2013). Conceptually, it shows that people prefer a quality of landscape around them, but it depended on how they perceive the landscape characteristics and situation of a place.

\subsection{Character of campus landscape}

In this context, students consider green spaces is a part of the university's image and comprise an intrinsic element of the character of the campus (Speake et. al., 2013). A campus is a hub of activities that serve a populace as both an environment for learning activity and a public space for leisure events (Gumprecht, 2007). It is especially true of campuses because they located in distinctive character of cities which face various concerns and demand for facilities and securities. There are some of the campuses more open and inviting people nearby, as such they provide an attractive landscape couple with good facilities and security concern. In conjunction, a beautiful campus can significantly add to the positive image of a town or city, thus has benefits beyond the educational sphere (Gumprecht, 2007). Dober (2000) supported that, a green space campus enhances the improvement of the image of the city.

The previous researcher stated that students appreciate and value the campus landscape for aesthetic, social and relaxation functions, well managed and maintained, formal and garden-style landscape (Speake et.al., 2013). The study by Speake et. al., (2013), highlighted the importance of landscape in the campus not only of the intrinsic aesthetic quality but also the fact that it is so obviously cared for and maintained to a high standard. Likewise, the selection of favourite areas within the campus not based on size, but on design, excellent quality, location and distance or convenience (Speake et. al., 2013). This character shows that the image of cleanness is one of quality that influences the student selection.

In contrast, the study by Abu Ghazzeh (1999) mentions that the selection of favourite areas in the campus outdoor spaces based on a combination of settings, landscape, people, individual experiences, and in the context of other spaces. In that study, students searched for unique outdoor spaces couple with activities that they like to pursue which differ from the academic life as usual. Abu Ghazzeh (1999) revealed that some students who expressed feeling like a home tend to prefer to be in the wooded environment. Abu Ghazzeh (1999) also cited from previous researchers that landscape preferences correlate with a demographic profile, landscape exposure, social class and place of residence. Subsequently, the perception of the campus landscape design must be examined in part as an attribute for the university to provide the quality of outdoor campus space. 


\subsection{Spatial landscape preferences}

Bonnes et al. (2011) have explored that the factor that contributes to ambivalent attitudes towards green space is involved social psychological and they have noted that there are still gaps for us to understand why people use spaces in their diverse ways. According to Griffith (1994), students critically select their university for further study always depend on the perception of the campus. Therefore, the quality of learning environment in the university must be considered the aesthetic as well as a role in the display image of campus. Abu Ghazzeh (1999) stated that campus outdoor areas ought not to be treated as leftover spaces. Careful consideration should be given to the overall placement and setting of the outdoor study spaces. (Abu-Ghazzeh,1999).

Zube et. al., (1982), have identified four general paradigms in landscape preferences which are an expert paradigm, psychophysical paradigm, cognitive paradigm and experiential paradigm. Referring to this study, psychophysical and cognitive paradigm was related. Both paradigms involve public as assessors on landscape quality which derived information from their visual perception and association with landscape properties. The study by Mirza (2016), landscape preferences mostly depend on people judgment and the appreciation towards the space to be assessed by a researcher. Then, it will reflect how the landscape and students communicate in their diverse ways.

Universities with attractive green space areas often highlight these as attributes which contribute positively to the student experience and the image of the university (Speake et. al., 2013). Griffith (1994) agreed and suggested that university priorities should include creating an attractive campus landscape. The landscape would have impressed the viewer and stimulate the motivation to be in there (Noriah et. al., 2015). That supported by Shuhana et. al., (2007), a landscape is not just a collection of educational facilities, but it is more than that which intellectually stimulating and aesthetically pleasing for students.

\subsection{Methodology}

This study was used structured interviews to collect the data at three selected Research Universities (RUs) in Malaysia. The Malaysia government initiated five from 20 public universities, which are; Universiti Malaya (UM), Universiti Sains Malaysia (USM), Universiti Putra Malaysia (UPM), Universiti Kebangsaan Malaysia (UKM) and Universiti Teknologi Malaysia (UTM). The reasons of selected RUs as a site study because these universities are among the high-ranking campus that chosen by students to further study. However, this study only chose three RUs; USM, UM and UPM. This three RUs selected have distinctive characteristics in term of background and location of the universities. USM consists of the main campus in the island of Penang with present about 416.6 hectares. The main campus of USM situated on the hill that provides a scenery towards Penang bridge. Whereas, UM is known as the oldest university in Malaysia. The campus consisted of 373.12 hectares and situated in the southwest of Kuala Lumpur which congested with development. The main campus of UPM in Serdang is up to 1108.103 hectares. Historically, UPM was known as agriculture school before they extended and included a various area of studies.

This study was a preliminary survey that was using structured interviews questions. The questions composed with favourable outdoor spaces on campus and interest or reasons to utilise the spaces attempting to find out the connectivity between spaces and activities. The respondents were asked to answer the questions by referring to their experience and observation on the spaces that frequently used by them or the other students. The sample used in this study was a random selection of 20 students for each selected RUs. After the surveyed completed, spatial analysis was performed by researchers. The spatial analysis was carried out using a thematic analysis and recorded in the tabular form. The respondents' answer was analysed based on the spaces cluster into subtheme consensus of the researchers.

The study investigated focused only on leisure spatial characteristics that become intimate spaces among the students. However, many other spatial characteristics which not only for leisure activities was not examined such as spaces between buildings, faculties, or collages. Accordingly, different spaces have different characters. Furthermore, the respondents focused only on students' spaces which result only from students' perception rather than preferences of the whole campus community. Besides that, a limitation of the study also is the external validity which the plants as a flexible variable. In a real situation, plants are the living elements that can change the appearance during their lifespan cycle. Additionally, students may perceive the outdoor spaces from different angles. All these factors may influence the different perception and taste of their spatial characteristics.

\subsection{Result and Discussion}

\subsection{Preference about campus landscape}

There were 60 respondents from three site surveys have participated. According to Table 1, respondents have answered the most pleasant outdoor space on their campus.

Table 1. Ranking of spatial landscape preferences

\begin{tabular}{llll}
\hline Spatial Landscape Character & USM & UM & UPM \\
\hline Open space & 3 & 1 & 2 \\
Semi-open space & 4 & 4 & 4 \\
Recreational space & 2 & 2 & 1 \\
Natural space & 5 & 3 & 3
\end{tabular}


The spatial characters have divided into five landscape types which are in the group of open space, semi-open space, recreational space, natural space and viewing space. Ranking number 1 is the highest rank and number 5 is the lowest rank. Open space has categorised according to the spatial characteristics that consist of a square, plaza or courtyard couple with the landscape facilities provided and plant composition. Semi-open space classified the area that comprises of canopy or wall but not to block the views from inside to outside or vice versa. The following was a recreational space that has the character of active space and support with exercises facilities. Next, the group of natural space was defined as an area that full of vegetation and water bodies. Lastly, viewing space was categorised as a unique space used for viewing the borrowed landscape or other features in the campus. From the respondents' answered in Figure 2, there are the different preference on spatial landscape character.

\section{USM}

Prefer borrowed view - has amazing view towards the sea, the Penang bridge, plants are shaded and enframe the view Location - the hilly area

\section{UM}

Prefer open space - uncomplicated design couple with landscape facilities and wi-fi connection. Shade trees and low shrubs define the space character as a special zone

\section{UPM}

Prefer recreational space - a wide range space provide multiple activities, suit for exercises, sight-seeing, and other leisure activities, plants variety in sizes but dominant by large, shade trees and open lawn

Fig. 2: The most preferred outdoor spaces

Respondents from USM mostly answered that they often used the viewing area which namely as "Bukit HEP" in USM as the most popular space. That space has an amazing view towards the sea and the Penang bridge, and more delightful during night view. The planting composition is arranged naturally but enframes the view. However, the respondents from UM and UPM almost all not respond to answer the viewing space as popular area. As mention in the background of site study, USM located on the hill site which exhibits the vista island. But, UM and UPM both situated next to the multifaceted location and in the horizontal area. Therefore, most of UM respondents accounted open space as a desirable area for leisure activities as compared to UPM respondents answered recreational space. The landscape setting at the UM open space designed with simple planting composition and completed with facilities such as benches, kiosk and most importantly wi-fi connection. The composition of shade trees and low shrubs create a barrier with another space and define the space character as a special zone. In contrast, UPM recreational space has a wide range of area for exercises, sight-seeing and other leisure activities. The wider area gives a chance for students to expressed various actions not limited to sports activity only. At this area, the plants have the variety of sizes but dominant by large, shade trees and lawn.

The preference shows that the results agreed with previous researchers. Almost all students need a space for release their mind, and the scholars have revealed the natural view as a remedy for stress and mental fatigue (Dongying and Sullivan, 2016). Furthermore, frequently access to view the natural setting make their life more happy and enjoyable (Kaplan and Kaplan, 1989). Even though UM and UPM do not mention about viewing the area as their preference, but the open space and recreational space character in their campus have a clear view to the outside and vice versa. Lawn and low shrubs function as divider and connection of space, not act as blockade area. Only USM has preferred viewing area due to the strategical location of the university. Perhaps, the other universities with the flat and horizontal area should strategies the viewing space to encourage the usage in the campus area.

\subsection{Less preference about campus landscape}

According to Table 1, semi-open space has the same rank from different universities. The respondents possibly answered that because of the character of partially open or close space was moderately less preferred due to the barricade elements. The result shows that most students need a free space but have some shade to prevent from direct sunlight. In conjunction with natural space, both UM and UPM respondents also moderately choose that space on their campus, while less preferred in USM. Most of the natural space in these universities was lack of maintenance coupled with the lack of attention on the landscape provided. According to Abu Ghazzeh (1999), the landscape in campus ought not to be treated as leftover spaces. That is supported by Speake et.al., (2013), that students cared about maintained and preferred to a high standard landscape setting. Maintenance is a critical part of landscape management. Therefore, careful consideration on plants selection and design must be a primary concern. Highly maintenance of the landscape could be reduced through plants with little care species should be planted and the arrangement of plants also will overcome the maintenance issue. Moreover, the simple composition of plants recommended because it is not only to reduce maintenance but also on the safety issue. Simple composition could be used principle of repetition, order, transition, rhythm or harmony in planting design.

\subsection{Reasons of utilisation outdoor campus space}

The result from the structured interview with respondents found most of the intention to use the outdoor campus space was to release stress through leisure and recreational activities. Respondents mostly were youth generation that has an active attitude which needs the space to express their movements. However, respondents were not aware of the planting design in their outdoor space, but they can recall the dominant landscape properties such as shade trees, lawn and water bodies. Most of the answers were shade trees which it could be the significant element in the planting design for outdoor campus space. Shade means the canopy of the trees should be a spreading, horizontal or oval canopy shape. Comfortable is one another reason to ensure the students utilised the spaces. 
According to the response of students, they feel comfortable to be under the towering trees completed with other landscape facilities compared to be under the structured roof. That supported the result of less preference area which is semi-open space. But place under the trees contrasted with the natural area that also not preferred by students. This conflict derived for the natural space with lack of maintenance and dropped the preferences towards the natural area.

\subsection{Conclusion}

This study highlights that most of the students prefer to be outside from classroom to release their mind and body refresh. As stated by previous researchers, outdoor space with connecting to landscape quality will engage the positive impact to student performance (Dongying and Sullivan, 2016; Stephen et. al., 2014; Speake et. al., 2013; McFarland et. al., 2008). Landscape with leisure setting preferred because it is not only provided non-academic life as usual but also offer better environmental quality for campus image development. It is also aligned with Speake et. al., (2013) where the image of campus space should be considered the landscape as a critical component in the development. The space design must have cooperated with plants to ensure the functionality and maintenance or safety issue on campus. These spaces should treat as the main area in developing landscape in universities. Furthermore, the landscape design that considers students preferences may increase their satisfaction and strengthen the positive values while utilising the preferred spaces. This study provided a foundation for present and future research to enhance studentcentred learning and also underpinning the decision making regarding designing and planting the right plants in the campus.

\section{Acknowledgements}

The authors would like to thank to Universiti Teknologi Mara, Perak Branch for continuous support. High appreciation also expressed to our participants for their time and efforts.

\section{References}

Abu Ghazzeh, T. (1999). Communicating Behavioural Research to Campus Design, Factors Affecting Perception and Use of Outdoor Spaces at The University of Jordan, Journal of Environment and Behaviour. 31(6), 764-804.

Bonnes, M., Passafaro, P., Carrus, G. (2011). The Ambivalence of Attitudes Toward Urban Green Areas: Between Pro-environmental Worldviews and Daily Residential Experience. Journal of Environment and Behavior. 43(2), 207-232.

Dasimah, O. (2009). Assessing Residents' Quality of Life in Malaysian New Towns. Asian Social Science. 5(6), 94-102.

Dober, Richard P. (2000). Campus Landscape: Functions, Forms, Features. John Wiley \& Sons. United States of America.

Dongying Li, William C. Sullivan. (2016). Impact of views to school landscapes on recovery from stress and mental fatigue. Journal of Landscape and Urban Planning (148) 149-158.

Griffith, J.C. (1994). Open space preservation: An Imperative for Quality Campus Environments. Journal of Higher Education. 65(6), 645-669.

Gumprecht, B. (2007). The campus as a public space in the American college town. Journal of Historical Geography. 33(1). 72-103.

Hamaideh, S.H. (2011). Gender Differences in Stressors and Reaction to Stressors Among Jornadian University Students. International Journal of Social Psychiatry. 58(1), 26-33.

Kaplan, R., Kaplan, S. (1989). The experience of nature: A psychological perspective. Cambridge University Press, New York.

McFarland, A.L., Waliczek, T.M., Zajicek, J.M. (2008). The Relationship Between Students Use of Campus Green Spaces and Perceptions of Quality of Life. Horticulture Technology, 18, 196-319.

Mirza, L. (2015). Windowscape A Study of Landscape Preferences in an Urban Situation. The University of Auckland. New Zealand.

Noriah O., Noralizawati M., Mohd Hisham, A., Mohd Ali Waliyuddin A.R. (2015). Landscape Visual Studies in Urban Setting and its Relationship in Motivational Theory. Procedia - Social and Behavioral Sciences, 170, 442-451.

Noralizawati, M., Noriah, O., \& Mohd Hisham, A. (2011) Assessing the Visual Quality of the Rainforest Trail at Penang Botanical Garden. Unpublished research report, Research Management Institute, Universiti Teknologi MARA.

Noralizawati, M., Noriah, O., \& Mohd Hisham, A. (2012), Value of Nature in Life: Landscape Visual Quality Assessment at Rainforest Trail, Penang. Procedia - Social and Behavioral Sciences 50, $667-674$.

Shuhana, S., Ahmad Bashri, S., Hasanuddin, L., Norsiah, A.A., Rozeyta, O., Masliyana, M.N. (2007). Kriteria Reka Bentuk Persekitaran Kampus yang Kondusif bagi Institusi Pengajian Tinggi di Malaysia. Research Report. Universiti Teknologi Malaysia.

Speake, J., Edmondson, S., Nawaz, H. (2013). Everyday Encounters with Nature: Students' Perceptions and Use of University Campus Green Spaces. Journal of Studies and Research in Human Geography 7.1. 21-31. 
Stephen Siu Yu Lau, Zhonghua Gou, Yajing Liu (2014). Healthy Campus by Open Space Design: Approaches and Guidelines. Frontiers of Architectural Research, 3(4), 452-467.

Ulrich, R.S. (1979). Visual landscapes and psychological well-being. Landscape Research. 4(1),17-23.

Ulrich, R.S. (1981). Natural versus urban scenes: Some psychophysiological effects. Journal of Environment. Behaviour. 13(5):523-556.

Zube, E.H., Sell, J.L., Taylor, J.G. (1982). Landscape perception: Research, application and theory. Journal of Landscape Planning, Volume 9 (1), 1-33. 